\title{
ESTILIZACIÓN DE LA MONSTRUOSIDAD: NUEVAS CONCEPCIONES DEL SER MITO- LÓGICO Y SU RESIGNIFICACIÓN COMO OTREDAD AMENAZANTE EN SERIES TELEVISIVAS FANTÁSTICAS
}

\author{
Ana Karen GrÜnIG \\ Universidad Nacional de Villa María (UNVM) \\ karengrunig@gmail.com
}

Recibido: 15-01-2014

Aceptado: 29-04-2014

(a) (1)

RESUMEN

Valorando la potencialidad del dispositivo televisual para propiciar la reflexión acerca de procesos socio-históricos, en el presente abordaje nos interrogamos acerca de la construcción del ser mitológico y su reconfiguración como otredad amenazante en las series televisivas fantásticas Being Human UK (BBC Three, 2008-2013) y Once Upon A time (ABC, 2011-2013) asumiendo la estilización de la monstruosidad y/o de la extrañeza como una novedosa estrategia que propone el diseño de seres sobrenaturales que atentan contra los estereotipos más convencionales y adoptan los cánones de belleza y normalidad establecidos en la sociedad actual.

PAlabras Clave: Estilización de la monstruosidad, mitos, otredad amenazante, series televisivas fantásticas.

\section{ABSTRACT}

Recognizing the potential of the televisual medium to encourage reflection about socio-historical processes, we wondered about the construction of the mythological being and its reconfiguration as threatening otherness in the fantastic television series Being Human UK (BBC Three, 2009) and Once Upon A Time (ABC, 2011-2013). The stylisation of monstrosity and/or strangeness is considered an original strategy to generate supernatural beings that transgress conventional stereotypes and adopt standards of beauty and normality set out in contemporary society. 
KEYWORDS: Stylization of monstrosity, myths, threatening otherness, fantastic television series.

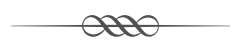

\section{INTRODUCCIÓN}

En cualquiera de sus acepciones lo monstruoso constituye una otredad, que por su desconocimiento y el alto grado de extrañeza experimentado por el ser o grupo de pertenencia durante el encuentro con «el otro», resulta amenazante (Boia, 1997; Calleja, 2005; Glockner, 1994; Santiesteban, 2000).

Ante el mínimo riesgo de perder la pretendida estabilidad propia y/o social, se impone la consigna del miedo como un mecanismo que contribuya a efectivizar la identificación del enemigo (Reguillo, 2000), que es invariablemente considerado como un otro-diferente. ${ }^{1}$ En consecuencia, tal como afirma Calleja (2005: 11) nos habituamos a proyectar en todo aquel que nos es distante y hostil una mirada deformante y aterradora exagerando sus deformidades y «monstruificándolo». Esta maniobra es ejecutada con frecuencia mediante un sinfín de historias populares de carácter sobrenatural tales como los mitos, las leyendas y los cuentos folklóricos, los cuales son frecuentemente recreados y actualizados por los mass media.

Así, la figura del ser monstruoso emerge con gran vitalidad en los relatos fantásticos del siglo xxI ocupando un lugar de privilegio en la serialidad televisiva inscripta en el drama de calidad. ${ }^{2}$ En este sentido, se vislumbra la explosión del fantástico como «el género predilecto para reflejar las ansiedades de una sociedad en crisis» (Cascajosa Virino, 2005: 194) en tanto se plantea transgredir las leyes que rigen la normal percepción de la realidad y desestabilizar las fronteras de lo seguro generando, de este modo, un efecto amenazante que lógicamente produce miedo.

1 En este estudio la categoría «otro-diferente» alude al otro-mitológico o al otro-monstruoso, y no refiere en ningún caso a la corriente antropológica del evolucionismo que concibe la construcción de la otredad por la diferencia.

2 Bajo tal concepción se hallan comprendidas aquellas ficciones que, en el marco de una lógica metatelevisiva, recuperan la calidad técnica y realizativa propia del arte cinematográfico y que, así mismo, logran alcanzar elevados niveles de audiencia. Entre sus rasgos distintivos identificamos la multiplicidad de tramas, la ambigüedad moral, el protagonismo coral, la hibridación genérica, la autorreferencialidad, fracturas espacio temporales, entre otras (Álvarez Berciano, 1999; Buonnano, 1999; Cascajosa Virino, 2005; Tous Rovirosa, 2008). 
En este marco, como una operación desorientadora y al mismo tiempo lúdica, el ser monstruoso irrumpe resignificado a través de la ocultación de su verdadera naturaleza y enmascarado bajo la apariencia de un ser humano corriente. Algunos estudiosos vinculan este fenómeno a las consecuencias de los atentados terroristas del 11-S (Pérez Pereiro, 2010), mientras que otros consideran que se trata de una estrategia novedosa que consigue intimidar a un espectador que ya no se sorprende ante amenazas corroídas por su previo conocimiento (Santiesteban, 2000). Lo cierto es que basta realizar un breve recorrido por el drama televisivo seriado de la última década para advertir numerosas producciones que reflejan las angustias de una sociedad que se siente en permanente estado de incertidumbre y amenaza. Uno de los casos más emblemáticos e influyentes en la producción televisiva de los últimos años lo constituye la serie Lost (ABC, 2004-2010), la cual no solo manifiesta estados de inseguridad, alerta y miedo desde el contenido temático (como la desconfianza entre los personajes por los «otros» y la incertidumbre acerca de sus destinos) sino también a través del diseño de estrategias de construcción espacio-temporal que dan lugar a la creación de universos alternos y desconocidos (Bort Gual, 2011).

Este fenómeno en el cual la otredad amenazante se encuentra enmascarada tornándose irreconocible a simple vista, se manifiesta mediante una serie de estrategias de representación que convergen en una estilización de la monstruosidad, procedimiento que alude a la preeminencia de seres míticos y/o sobrenaturales que, concebidos tradicionalmente bajo una naturaleza monstruosa, son diseñados bajo determinados cánones de belleza, de sentimientos y de valores establecidos en la sociedad actual. Específicamente, la estilización de la monstruosidad implica la configuración de seres mitológicos y/o sobrenaturales compuestos a partir de una dualidad identitaria que confluye en un híbrido entre lo humano y lo monstruoso; en consecuencia se instituye un otro-amenazante y un Nosotros-alertas de manera simultánea.

En este sentido, se erigen relatos que reflejan un nuevo sentido de la alteridad a través de una pronunciada orientación hacia la interculturalidad, la inclusión social y el desdibujamiento de los límites que definen lo bueno y lo malo aceptando lo no-humano como probable e insertándolo en universos diegéticos diseñados bajo las premisas de la «realidad corriente». De esta manera, el relato incluye la otredad sobrenatural relativizando su potencial amenazante, aunque para efectuarlo debe «des-otrerizarlo». Esta estrategia implica la modificación de sus aspectos más convencionales (que lo posicionaban sin duda en el extremo de lo malo, lo bestial y lo peligroso) y la incor- 
poración de las características más esperables y estereotipadas del ser humano del siglo xxI.

En este abordaje en particular, pueden dilucidarse diferentes estrategias y recursos que evidencian este fenómeno en las series televisivas fantásticas Being Human UK (BBC Three, 2008-2013) y Once Upon A time (ABC, 20112013). La primera asienta su narrativa en la convivencia de un vampiro, un hombre lobo y un fantasma que se unen en su afán por vivir como si fuesen humanos. ${ }^{3}$ Mientras que la segunda, propone un universo en cual aquellos cuentos mágicos que forman parte de la narrativa infantil global han sucedido en un tiempo inmemorial y cobran vigencia en el mundo que transitamos actualmente. De tal modo, construye dos mundos alternos: el Bosque Encantado, en el cual habitan todos los personajes de los clásicos cuentos de hadas, y Storybrooke, una nueva tierra que la Reina Malvada ha creado como fruto de un aterrador hechizo. Por tratarse de una serie que mixtura lo fantástico con lo maravilloso, hemos colocado el foco de interés en aquellos episodios en los cuales emerge con potencia el componente mítico. En efecto, los capítulos escogidos en este estudio son Red Handed ( $1^{\text {a }}$ Temporada, cap. 15) y Child of the moon ( $2^{\text {a }}$ Temporada, cap. 7), los cuales abordan el cuento de Caperucita Roja y su relación con el hombre-lobo/lobo feroz. Concretamente, en la primera temporada Caperucita descubre que ella misma es el hombre-lobo / mujerloba, mientras que en la segunda temporada teme por su transformación y conoce a su madre quien resulta ser una importante líder de una comunidad de hombre-lobos.

De este modo, presentamos a continuación algunas aproximaciones a partir de las cuales se instituye al otro-mitológico o monstruoso y se lo resignifica como otredad amenazante en las series televisivas fantásticas antes mencionadas.

\section{ENTRE MONSTRUOS, MITOS Y CUENTOS DE HADAS}

Considerando que el presente abordaje propone la estilización de la monstruosidad como una estrategia de representación del otro-mitológico reconfigurándolo como otredad amenazante, creemos oportuno apuntar algunas reflexiones vinculadas a las ideas de monstruo, mitos y cuentos de hadas,

3 En relación a la selección de los casos para su estudio, debemos aclarar que hemos escogido la serie Being Human (UK) y no su versión norteamericana Being Human (EE.UU.) en tanto percibimos que constituye una reproducción bastante similar aunque más extendida de su original; en ese sentido, consideramos que no aporta modificaciones notables que nutran la reflexión. 
así como el modo en el cual cobran nuevas significaciones en las series escogidas para el análisis.

En primer término, convenimos en que tanto los mitos como los cuentos y los agentes cargados de monstruosidad son asumidos como una construcción cultural. En efecto, es habitual que tales categorías sufran incalculables modificaciones originando múltiples versiones en función al contexto socio-histórico en el cual tengan vigencia, tal como las efectuadas por las series Being Human UK y Once Upon A Time acerca del mito del hombre-lobo, del vampirismo, de los fantasmas y del cuento Caperucita Roja.

Si bien no hay mayores acuerdos que demarquen las definiciones de los mitos, los cuentos y los monstruos, es notable como las diversas posturas circundan la discusión sujetándose a determinadas relaciones dicotómicas tales como realidad-ficción, ciencia-fe, natural-sobrenatural, racional-irracional, sagrado-profano, normal-anormal, humano-bestial o naturaleza-cultura, entre otras que ayudarían a comprender el mismo. ${ }^{4}$

Así, por un lado lo monstruoso es siempre concebido como una otredad, que puede asumirse como un ente diferente en tanto el observador se auto reconozca como el único patrón y modelo de referencia en términos de «normalidad». ${ }^{5}$ En este sentido, actúa por contradicción, puesto que debe alterar lo regular para dar lugar a un único espécimen a partir de la convivencia de naturalezas contrapuestas (Río Parra, 2003). Teniendo en cuenta que la irrupción de lo «anormal» genera desconcierto y extrañeza en la conciencia receptora, lo monstruoso resulta amenazante. En consecuencia, ante la conciencia del peligro es habitual adjudicar al otro-diferente todo tipo de carga negativa, demonizándolo y monstruificándolo (Calleja, 2005).

Desde esta perspectiva, la existencia del ser monstruoso exige una creencia en la probabilidad del acontecer sobrenatural o no-humano, como así también requiere de un reconocimiento de su extrañeza y la inmediata toma de conciencia del peligro que lo monstruoso transmite. Tal como señala Santiesteban, El temor al monstruo es vital para su existencia (2000: 124).

Ahora bien, en las series televisivas Being Human UK y Once Upon A Time lo monstruoso funciona como la matriz del relato, ya que más allá de

4 Resulta digno de señalar para este estudio que tal tipo de conciliación de órdenes contrarios prevalece también en las categorías definitorias de los relatos fantásticos y de los estudios antropológicos, con lo cual, si se entrecruzan recíprocamente dichas relaciones dicotómicas, pueden potenciarse y profundizar así la comprensión del fenómeno en su conjunto.

5 Esta afirmación alude al etnocentrismo como una condición necesaria de la alteridad. Concretamente, en un encuentro con el otro-diferente el observador tiende a considerarse un ser superior; por lo tanto, se auto concibe como modelo de referencia para poder aprender al otro como una otredad propiamente dicha (Krotz, 2004). 
contener personajes de esencia bestial como un vampiro, un fantasma, un hombre-lobo y una mujer-loba respectivamente, se cuestionan las categorías preestablecidas de normalidad y anormalidad dotando de un carácter ambiguo a la noción de alteridad.

Específicamente, en Being Human UK los protagonistas se reconocen como una otredad amenazante pero, como reniegan de ello, deciden enmascararse. La tensión se expande cuando los personajes deben decidir si permiten que emane su instinto bestial o si se auto controlan en su afán de vivir como humanos. Con lo cual la identidad monstruosa de los personajes funciona como el conflicto dramático medular de la trama seriada.

En el caso de Once Upon A Time lo monstruoso se manifiesta explotando el temor de lo desconocido. La ocultación de la naturaleza monstruosa de Caperucita no solo se encuentra en la comunidad sino también en el propio personaje. En Storybrooke, Rubi (Caperucita hechizada) ignora su identidad debido al conjuro de la Reina Malvada; pero en el Mundo Encantado es Abuelita quien engaña a todos los personajes de la diégesis -especialmente a Caperucita- ocultando que la joven se convierte en hombre-lobo/mujer-loba durante todas las noches de luna llena. La revelación de semejante secreto origina un personaje que padece su destino al mismo tiempo que intenta reconstruir su propia identidad, que de cualquier modo es siempre una otredad (en algunas ocasiones amenazante y en otras, protectora).

Por otra parte, el conocimiento público de los monstruos divulgado a lo largo de la historia de la civilización puede ser objetivado en tanto funcionan como personajes de un relato. Estas narraciones pueden hallarse bajo la forma de cuadernos de viaje, de diarios de campo, de bitácoras, etc., realizados durante expediciones viajeras o estudios antropológicos; pero también, pueden consistir en historias de ficción con grandes componentes fantásticos y maravillosos como los mitos, las leyendas y los cuentos folklóricos o los clásicos cuentos de hadas.

En cuanto a los mitos, deducimos que son ante todo sistemas inteligibles que proveen explicaciones que desde la lógica racional y la realidad empírica son imposibles de ofrecer. En efecto, la gran mayoría de los estudiosos acuerdan en que un mito es una narración tradicional cimentada culturalmente, transmitida de generación en generación y perdurable en el tiempo; igualmente, intentan brindar explicaciones acerca del origen de diversos fenómenos, naturales o morales, o bien de lugares, del hombre mismo y del universo en cual éste vive. Asimismo, parecen transcurrir en un pasado atemporal (vinculado al tiempo de los orígenes) y suelen referir a un espacio distinto del 
cotidiano aunque reproducen determinadas referencias culturales de la sociedad en la que tienen vigencia (Colombres, 1994-1995; Elíade, 1991; García Gual, 1987; Herrero Cecilia, 2006; Kirk, 1985).

Pues bien, las series escogidas para el análisis recuperan los mitos del hombre-lobo, del vampirismo y de la vida después de la muerte; es decir, mitos acerca del hombre mismo y de la imagen distorsionada que éste puede asumir. En este sentido, los monstruos o entes sobrenaturales que integran dichos relatos son concebidos como un espejismo o reflejo de lo más terrorífico y temible del ser humano (Boia, 1997; Calleja, 2005; Río Parra, 2003). Así, las modalidades que el hombre puede comportar van adecuando sus cristales a diferentes períodos y lugares. Precisamente, el anclaje temporal colocado en la actualidad que las series efectúan en mitos que poseen referencias en tiempos remotos, así como la des-otrerización del ser mitológico o monstruoso a través de su estilización física, ética y moral, insinúa la propagación de un nuevo sentido de la alteridad cuestionando los prejuicios que determinan la concepción del otro-diferente.

Otra dimensión significativa que envuelve la idea de mito y que, según nuestro criterio, constituye una de las cuestiones esenciales que lo distingue de los cuentos populares y los cuentos de hadas, es su existencia real o inventada. De las múltiples perspectivas teóricas al respecto, coincidimos con Elíade (1991), quien argumenta que si bien el mito no habla de lo que ha sucedido realmente, intenta explicar acontecimientos o fenómenos que en verdad existen. Por ejemplo, el mito que explica el origen del mundo es verdadero en tanto el mundo existe en la realidad de las sociedades. En cambio, el cuento folklórico o popular es experimentado como una historia inventada que, aunque pretenda imitar la realidad, siempre predomina la conciencia de su carácter ficticio.

Una de las variantes que pueden asumir los cuentos folklóricos o populares son los cuentos de hadas. Al igual que los anteriores, consisten en relatos falsos e irreales aunque entre sus personajes deben hallarse seres monstruosos y/o sobrenaturales. Asimismo, más allá de las finalidades primordiales que posea, como la sátira, la aventura, la enseñanza, la ilusión, o la suma de todas ellas, estos cuentos hacen uso del poder de la magia como un componente fundamental que en ningún caso debe burlarse ni ridiculizarse (Tolkien, 1998). Bien por el contrario, la magia exige respeto y seriedad, porque, tal como lo mencionan reiteradamente a lo largo de toda la serie Once Upon A Time, «toda magia tiene un precio» y como tal puede brindar extraordinarias soluciones o puede dar a luz a la mayor de las oscuridades. 
Tal como lo citamos previamente, Once Upon A Time recupera los clásicos cuentos de hadas y los adapta a la cultura del espectáculo del nuevo milenio. En los episodios escogidos, se aborda el cuento Caperucita Roja en una fascinante y original mixtura con el mito del hombre-lobo/mujer-loba.

Como sabemos, este cuento es uno de los que más se ha adaptado a distintas regiones y épocas pasando por las famosas publicaciones de Perrault y de los Hermanos Grimm hasta otras versiones con vestigios en tiempos remotos en las que podrían existir referencias a un hombre-lobo que posteriormente fue sustituido por el lobo feroz. ${ }^{6}$

Ahora bien, recuperando la premisa aludida inicialmente en relación al carácter cultural que admiten los monstruos, los mitos y también los cuentos de hadas, sostenemos que las diversas versiones de este cuento erigen novedosas significaciones que responden a determinadas vicisitudes contextuales. Así, la versión publicada por Charles Perrault en 1697 representaba una metáfora de lo sexual (luego ensayada en el campo del psicoanálisis) mientras que la propuesta infantil de los Hermanos Grimm de 1812 lo convierten en un cuento de hadas que reproduce de manera sobrevalorada la estructura familiar fundada en una imagen patriarcal y la obediencia como la senda adecuada que conduce hacia el final feliz.

Por su parte, desde una concepción teórica de género, Catherine Orenstein (2003) considera que Caperucita Roja en todas sus representaciones denota una insinuación sexual en la cual, ingenua y tentadora, cae en las garras de un lobo sediento. Ello podría advertir el sello que este cuento imprime en una sociedad que se halla debatiendo por la igualdad de género a través de la aparición en los medios de comunicación de cientos de Caperucitas desde una mirada vengadora y justiciera.

Dicha reflexión resulta muy significativa si pensamos que la serie Once Upon A Time ( $1^{\text {a }}$ Temporada, cap. $15 ; 2^{\text {a }}$ Temporada, cap. 7 ) nos presenta una Caperucita sexy, provocadora y osada que no recuerda a la niña tímida e ingenua que vivía en ese mundo inmemorial al que ya no podrán regresar. Pero además, la serie nos muestra ese universo en el que habitaban todos los personajes de los cuentos de hadas; allí Caperucita vuelve a desafiarse, porque no solo es una joven atractiva e indefensa sino que es simultáneamente el loboferoz/mujer-lobo. Es decir, mientras la mayoría de las versiones acreditadas de Caperucita Roja conservan las figuras centrales del relato (Joven-Lobo-

6 Existen registros de un cuento de tradición oral que describe las aventuras de una niña y su relación con un bzou, una especie de hombre-lobo. Sin embargo, tal narración no imprime la alta carga dramática de las versiones que circulan con mayor frecuencia en la actualidad (Guàrdia Calvo, 2007). 
Abuela) aún modificando sus apreciaciones, la propuesta de Once Upon A Time complejiza su estructura combinando dos personajes centrales que originan un híbrido entre Caperucita, el lobo feroz y un hombre-lobo resignificado bajo la imagen de una mujer-loba. Explícitamente, la serie constituye un relato en el cual se desgarran las fórmulas tradicionales consiguiendo acrecentar el desconcierto y el interés del espectador más experimentado.

Más allá de las diferencias conceptuales que los mitos y los cuentos poseen entre sí, además de las peculiaridades que asumen en los casos abordados, es preciso tener en cuenta que estos tipos de relatos comparten la labor de «demonizar» o «monstruificar» al otro-diferente volviéndolo profundamente amenazante (Calleja, 2005). Sin embargo, su significativa presencia en el drama seriado de la última década sugiere que tal demonización se relativiza mediante una estilización de la monstruosidad que explicitamos a continuación.

\section{DesAfíos Al GÉNERO FANTÁSTICO EN LA SERIALIDAD TELEVISIVA ANGLOSAJONA}

La constitución del ser mitológico y la estilización de la monstruosidad como estrategia delineadora de un control socio-estético de la otredad amenazante se encuentra comprendida en un proceso que, según nuestro criterio, inaugura otras maneras de concebir al género fantástico y lo desarrolla desafiando algunas de sus propiedades definitorias. Precisamente, advertimos una superación de la conflictiva co-existencia de naturalezas contrarias acaecidas en un universo diegético para sobrevenirse en la constitución primaria y esencialista de los personajes. Es decir, en estas nuevas propuestas, la problematización emanada por la convivencia de fenómenos que corresponden a órdenes contrapuestos como lo natural/sobrenatural, lo racional/irracional, lo normal/anormal, entre otros (Barrenechea, 1996) no sólo acontece en el plano del accionar dentro del mundo diegético, sino que además, opera en la configuración identitaria de los personajes. De manera que estas narrativas constituyen personajes mediante dimensiones propias de la entidad sobrenatural (como el instinto asesino del hombre-lobo o de la mujer-loba, dependiendo de la serie) añadiéndoles rasgos identificables en los habitantes de la sociedad actual. Esto último se manifiesta, por ejemplo, bajo una apariencia estereotipada del joven del siglo xxI o a través del diseño de personajes que atraviesan etapas de rebeldía en una ofuscada búsqueda del querer ser. Si repasamos aquellas categorías acerca de lo monstruoso que lo definen como una existencia plural -dada su conformación muchas veces híbrida-compren- 
demos la coherencia interna que posee el relato a través del diseño de este tipo de personajes.

Así mismo, y directamente ligado a este fenómeno, observamos en ambas series televisivas una mutación en el punto de vista de la narración, ${ }^{7}$ si lo reflexionamos desde el postulado de Todorov (1970) para quien el fantástico no es más que un estado de vacilación que experimenta el personaje y/o el lecto-espectador ante la irrupción de una extrañeza en un mundo que les resulta familiar. En las series televisivas que abordamos, el punto de vista del relato está situado en un ser extraño, mítico y monstruoso que habita un mundo impregnado de leyes naturales y sobrenaturales al mismo tiempo. En consecuencia, las sensaciones de desconcierto, incertidumbre y miedo, propias del fantástico, se encuentran vinculadas a situaciones de múltiples índoles a las que son expuestos los protagonistas, aunque se observa una fuerte tendencia a la aparición de estas emociones cuando prevalece un acercamiento a la revelación del secreto identitario, ya sea del propio protagonista que aún desconoce su verdadera naturaleza o bien ante una sociedad en la cual se halla enmascarado como un habitante corriente. Esta alusión puede observarse en los dos

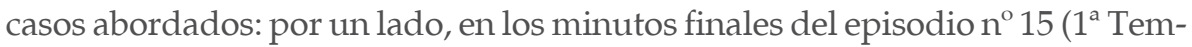
porada) de Once Upon A Time, Caperucita atraviesa una sensación extrema de sorpresa, confusión y angustia al descubrir que ella es el lobo feroz que amenaza a todo el poblado y que acaba de asesinar a su gran amor; es decir, descubre que es una mujer-loba; ${ }^{8}$ por otro lado, durante el cuarto capítulo de Being $\mathrm{Hu}$ man UK ( $1^{\text {a }}$ temporada) Mitchell, el vampiro, es atacado por sus vecinos cuando descubren un video en el que dos de su especie mantienen relaciones sexuales. En este caso, si bien los humanos desconocen que Mitchell es un monstruo, lo rotulan como un otro-amenazante de la estabilidad social pretendida por considerarlo un pervertido sexual (nuevamente observamos la monstruficación del otro-diferente). Esta situación no sólo consigue una reacción negativa por parte de los miembros de la comunidad sino que además pone en duda el plan de los protagonistas: en el siguiente episodio George, el hombre-lobo, reclama: «Nos hemos estado engañando al pensar que seríamos aceptados aquí por verdaderos seres humanos, ¡somos monstruos!» (1 $1^{\text {a }}$ Temporada, cap. 5).

7 Cabe aclarar que el punto de vista del relato se encuentra determinado por la historia del protagonista, que es en definitiva la que se pretende contar (Del Teso, 2011).

8 Es importante mencionar que en esta serie, la revelación de la «verdadera» identidad de Caperucita genera una rotunda modificación de roles, porque de ser una joven ingenua e inofensiva se convierte en el monstruo más temible del poblado. En este sentido se diferencia de una serie similar como Grimm (NBC, 2011-2014) en la cual la revelación del secreto identitario no produce mayor variación de roles más que en lo atinente a consolidar al protagonista como el héroe del relato. 


\section{ESTILIZACIÓN DE LA MONSTRUOSIDAD EN EL PLANO DE LA APARIENCIA}

Basta descubrir en la configuración identitaria de los personajes su naturaleza extraña (atendiendo a cualquiera de sus dimensiones físicas, psicológicas y morales) para que sean considerados como una otredad amenazante, lo cual ocurre de inmediato en las dos series en cuestión. Concretamente, la identificación habitual con los personajes se obstruye sólo por situarnos frente a la pantalla con protagonistas como un fantasma, un vampiro y un hombrelobo o una «mujer-loba», los cuales, desde las leyes que rigen la percepción que poseemos de la realidad, son asumidos como entidades que ponen en peligro la seguridad social pretendida.

Este fenómeno se potencia aun más en tanto prevalece una ocultación de la «verdadera» apariencia de los personajes y de sus metamorfosis enmascarándose bajo un aspecto reconocible como propio de lo humano.

Sin embargo, consideramos que esta otredad amenazante se reduce a partir de una composición fisiológica de los personajes que se asemeja más al prototipo de joven del siglo xxI que al mito tradicional o creencia sobrenatural que encarnan, manifestando así una vigorosa orientación a rejuvenecer y embellecer estas criaturas extrañas. A modo de ejemplo, describimos el caso del vampiro Mitchell presente a lo largo de toda la serie Being Human UK, el cual establece un diálogo con el mito que encarna desde una transfiguración en función a los cánones y modelos estéticos de la actualidad. Al respecto, sabemos que la concepción clásica del vampirismo es reconocida por indicios como la delgadez y palidez, los colmillos pronunciados y las orejas puntiagudas, la capa negra de terciopelo -o al menos un atuendo oscuro-, el peinado a la gomina, etc. Sin embargo, el personaje no presenta esos atributos o los mantiene en un grado mucho más leve: posee una tonalidad clara en su piel pero no conserva la palidez de un vampiro como lo reconocemos convencionalmente; viste ropa oscura pero el atuendo corresponde al de un ser humano corriente del mundo actual; es delgado y posee facciones más bien puntiagudas que redondeadas, pero no representa el «modelo» de rostro de un monstruo que se alimenta de sangre humana, etc. De ello podemos reflexionar acerca de la categoría estética que admite lo bestial y elucidar que la simple ecuación del monstruo con la fealdad se vuelve insuficiente.

Siguiendo esta dirección, sostenemos que además de tratarse de una estrategia en pos de elevar los niveles de audiencia, este recurso intenta dar cuenta de dos fenómenos de mayor relevancia para este estudio: por un lado, estas nuevas configuraciones de los personajes abocados a desdibujar cons- 
tantemente los límites entre la realidad y la ficción constituye una característica clave en los relatos fantásticos televisivos contemporáneos, particularmente en el drama de calidad. Y por el otro, la atribución a seres mitológicos de determinadas características físicas que son distintivas del joven del nuevo milenio contribuye a potenciar el efecto de verosimilitud necesario en aquellos relatos fantásticos fuertemente instituidos bajo el arte de la "mímesis» (García Ramos, 1987). De manera que los personajes de estas series televisivas reflejan al joven actual sumido en una profunda crisis, envuelto en un mundo cambiante y en el que la supervivencia depende del desempeño individual.

Finalmente, consideramos que el empleo de los recursos técnicos y realizativos constituye otra dimensión significativa en la representación del ser mítico como otredad amenazante. En tal sentido, el nivel imagético (sonoro-visual) del relato alcanza un nivel de perfección audiovisual que permite gozar de cada detalle implicado en la coexistencia de lo natural y lo fantástico, no solo en el diseño de universos diegéticos creados con un alto grado de verosimilitud sino también en las instancias de transformaciones antropomórficas sobrellevadas por los personajes. De este modo, las herramientas de la producción audiovisual establecen un canon visual cromático que configura la «notredad»y, simultáneamente, se fusionan enfatizando la espectacularización del mito o realidad sobrenatural. Este fenómeno es muy notable en Being Human UK cuando a George, el hombre-lobo, no le queda más opción que transformarse en la casa que comparte con sus dos amigos, el vampiro Mitchell y el fantasma Annie ( $1^{\text {a }}$ Temporada, cap. 1). Esta escena denota una gran destreza audiovisual para exponer el modo en el que una bestia en su estado natural se manifiesta en un tiempo-espacio representado con un elevado nivel de verosimilitud.

\section{OTREDAD AMENAZANTE Y SU DISCUSIÓN CON EL DESTINO}

Otra sobresaliente característica destinada a esculpir una nueva concepción del ser mítico o monstruoso puede vislumbrarse en el diseño de personajes que atraviesan profundas crisis de identidad a partir de un permanente cuestionamiento de los ordenamientos éticos y morales esperables en los relatos fantásticos.

Desde esta dirección, a grandes rasgos deducimos que tales conflictos de índole existencial pueden derivarse por dos cuestiones: bien por desconocimiento y ocultación de la propia naturaleza bestial, o bien por la negación 
de la identidad que les ha sido impuesta. Seguidamente, explicitamos la manifestación de estas variantes en los casos estudiados.

Por un lado, Once Upon A Time ( $1^{\mathrm{a}}$ Temporada, cap. 15) quebranta la versión original tanto del cuento como del mito que encarna a partir de una representación de Caperucita Roja como una joven originaria del Bosque Encantado muy amable, ingenua y aventurera, que llega a descubrirse como el animal feroz más temido de la aldea. Mientras tanto, en Storybrooke (un universo figurado bajo las premisas de nuestra «realidad» que la Reina Malvada ha inventado como parte de un hechizo pretendiendo acabar con los finales felices de todos los personajes de los cuentos de hadas) Caperucita Roja presenta una identidad impuesta como «Rubi», una joven bella, sexy y osada que, en pleno ejercicio de la rebeldía, desea escapar de la protección de su abuela explorando nuevos horizontes y añorando un crecimiento personal. Exhibiendo una complejidad narrativa y anunciando un carácter lúdico, ${ }^{9}$ la serie efectúa la revelación del secreto identitario al final del episodio.

El desconcierto acaecido por el arrebatamiento y la ocultación de la verdadera identidad arroja a este personaje a una profunda discusión entre el querer y el deber ser como bestia y humano; es decir, por un lado aparece un deseo fuertemente vinculado a una naturaleza monstruosa que la alienta a atacar ferozmente a los humanos para alimentarse y por el otro, irrumpe una moralidad de la «notredad interna» que le imprime los límites entre el bien y el mal.

En el caso de Being Human UK, la crisis existencial que atraviesan los personajes sobrenaturales se origina a partir de una negación de la identidad. Concretamente, tanto el vampiro, como el fantasma y el hombre-lobo conocen su identidad pero reniegan de ello añorando ser los humanos que en algún tiempo fueron y que, de hecho, en algunos aspectos aún lo son. Como estrategia superadora, deciden ocultarse entre los humanos intentando parecerse en casi todas sus facetas, aunque deben luchar constantemente con la naturaleza bestial que les ha sido emplazada. Un ejemplo muy representativo de ello puede apreciarse en el capítulo $n^{\circ} 4$ ( $1^{\text {a }}$ Temporada) cuando Mitchell entabla una relación amistosa-paternal con Bernie, un niño del vecindario que sufre

9 Once Upon A Time se inscribe en un fenómeno metafóricamente denominado como Series Puzzles, noción proveniente del ámbito cinematográfico que en un estudio más amplio hemos decidido extrapolar al campo del drama televisivo y que designa al conjunto de producciones que implican la no-linealidad narrativa, la presencia de bucles temporales y la construcción de realidades espaciotemporales fragmentadas en estructuras enigmáticas determinadas por la disposición laberíntica de los acontecimientos. De este modo, las narrativas complejas encuentran su atractivo no sólo en los acontecimientos narrados, sino también en la exhibición de la maquinaria narrativa, que se dispone como un puzzle al que le faltan piezas que el espectador deberá encontrar y ubicar en el sitio correcto (Buckland, 2009; Calabrese, 1994; Mittell, 2006). 
de ciertas situaciones de exclusión. El hecho es que mientras comparten un momento juntos jugando a bolos, el niño se golpea y brota sangre en su rostro. Este acontecimiento pone a prueba el instinto del monstruo que en esta ocasión es vencido por lo humano. Es decir, Mitchell consigue resistir la tentación probando que los monstruos también pueden ser compasivos.

De este modo, la profunda pelea interior entre el bien y el mal y el conflicto por mantener el propio «control pulsional» de los personajes, no solo confiere nuevos modos de desentrañar las reglas del género fantástico sino que además se dispone como un mecanismo más para reducir la otredad amenazante, añadiéndole características de una «notredad» en permanente estado de alerta circundante en una sociedad que desconfía tanto del otro-diferente como de sí mismo. Se trata de otro recurso manifiesto de la estilización de la monstruosidad, mientras prevalece en el relato una modelación de los personajes míticos o sobrenaturales a partir de sentimientos y valores reconocibles en nuestro mundo actual.

Cabe señalar que esta estrategia se inscribe como una de las características más relevantes del drama de calidad. Nos referimos específicamente a la configuración de los personajes fundados en una ambigüedad moral donde nunca se es «ni tan bueno ni tan malo». En este sentido, consideramos que esta dimensión restituye la posición como otredad amenazante de aquellos personajes fantásticos representativos de seres míticos o sobrenaturales, puesto que si esta ambigüedad genera inseguridad en personajes de cualquier índole, más aún lo provoca en personajes extraños que pueden convertirse en entidades peligrosas y amenazantes.

\section{CONSTRUCCIÓN DE COMUNIDAD Y LA ESPERANZA DE LA INCLUSIÓN}

Ante la tensión generada a partir de la convivencia de dos identidades correspondientes a órdenes contradictorios, en ambas series se observa en los personajes una pretensión de construir nuevas comunidades, ${ }^{10}$ motor que se convertirá en un proyecto y estilo de vida.

Partiendo de esta premisa, advertimos la coexistencia discordante de dos universos o comunidades entre los que circulan los personajes: un mundo interior y un mundo exterior.

10 La importancia otorgada al sentido de comunidad puede identificarse también en la popular serie televisiva Buffy, la cazavampiros (WB, 1997-2001), en la cual los protagonistas, revelando una adolescencia heroica, descubren que unidos pueden vencer al vampiro enemigo como así también sobrellevar sus respectivos conflictos familiares (Cascajosa Virino, 2006). 
Por un lado, el mundo exterior es aquel universo en el cual se presentan situaciones, lugares y demás personajes que poseen características similares a las presupuestas en el mundo corriente. En consecuencia, es en este nivel territorial donde los seres míticos o monstruosos son reconocidos como otredad amenazante.

Y por otro lado, el mundo interior es el que ha sido construido por los propios personajes con nuevas leyes y reglas que les son propias y que, fundamentalmente, se adecuan a sus necesidades existenciales y resuelven las dicotomías que obstaculizan su accionar. Así, presumimos que el relato se desvía del mito convencional en tanto los personajes se alejan (ya sea por voluntad propia o por expulsión) de sus comunidades para formar otras nuevas. Concretamente, en Being Human UK a partir del primer capítulo, el fantasma, el hombre-lobo y el vampiro se unen bajo la proposición de seres monstruosos y/o sobrenaturales que quieren vivir como humanos, y entendemos que la materialización de esa comunidad se encuentra implicada en la creación de la morada en la que conviven. En el caso particular de Once Upon A Time, si bien la invención de este nuevo universo presentado como «Storybrooke» está a cargo de la Reina Malvada, es Caperucita Roja junto a los demás personajes de los cuentos de hadas quienes crean nuevas normas de convivencia y de aceptación ante la revelación del secreto identitario en un mundo que les ha sido impuesto ( $1^{\text {a }}$ Temporada, cap. 22). En este plano es donde los personajes adquieren una importante cantidad de dimensiones representativas de un «nosotros-alertas» que pueden resultar familiares para el espectador de la televisión contemporánea.

Ahora bien, retomando aquel principio elemental del relato fantástico que establece la alteración de las leyes que rigen el «universo real» para generar inestabilidad y producir un efecto de miedo (Barrenechea, 1996; Todorov, 2005; Roas, 2006) percibimos que en las series seleccionadas, los seres míticos y sobrenaturales se configuran como una otredad aún más amenazante cuando son transgredidas las leyes del mundo interior que las del mundo exterior. Esquemáticamente, entendemos que las dos series parten de una situación conflictiva inicial fundada en una situación de inestabilidad y alteración que proviene del mundo exterior. En Being Human UK tal situación se manifiesta ante el peligro de ser descubiertos y juzgados como otredad amenazante ( $1^{\text {a }}$ Temporada, cap. 4), y en Once Upon A Time la situación conflictiva supone la supervivencia en un sitio provisto de un ordenamiento natural contraria a los de su tierra originaria. Sin embargo, cuando esa instancia parece estar superada, el relato efectúa una transgresión de las leyes que los propios perso- 
najes han creado como posible resolución de sus conflictos (estrategia que inevitablemente despierta una inseguridad más profunda). Es decir, percibimos un fenómeno en el cual ni siquiera aquello que los propios personajes han erigido es capaz de asegurar su buen accionar ni su estabilidad emocional. Un ejemplo de ello se aprecia en Being Human UK, cuando el vampiro Mitchell muerde a la joven Laurent transformándola en un espécimen de su misma raza ( $1^{\text {a }}$ Temporada, cap. 1). Esta acción tiene dos profundas consecuencias que acentúan la amenaza. Una de ellas, es que se evidencia la debilidad de Mitchell ante su naturaleza monstruosa, pues no puede dejar de actuar como un vampiro y eso lo hace peligroso. Y la otra es que atenta contra un valor primordial de la historia como lo es la amistad, puesto que Mitchell no sólo ha transformado a Laurent sino que también ha puesto en riesgo el secreto que poseen conjuntamente los demás personajes protagónicos.

Por todo ello, deducimos que este particular tratamiento del factor sociológico en la construcción de los personajes míticos y sobrenaturales constituye un ingrediente fundamental a la hora de relativizar la configuración de los personajes como entidades amenazantes de la estabilidad social, tanto en el mundo exterior como en el mundo interior.

\section{CONCLUSIONES}

La estilización de la monstruosidad como una estrategia para enmascarar la otredad amenazante instituye un doble efecto en la producción de miedo. Por un lado, los casos estudiados relativizan el potencial amenazante cuando le añaden al monstruo ciertos valores éticos y morales propios del «nosotros» actual. Sin embargo, cuando la estilización se encuentra vinculada a la funcionalidad estética de estos seres sobrenaturales, los vuelven irreconocible a simple vista entre la multitud de seres humanos, con lo cual el estado de alerta se expande potenciando la amenaza del otro-diferente.

Asimismo, consideramos que estas series televisivas fantásticas reflejan una actitud positiva e inclusiva que acepta la existencia de nuevos seres que ya no son ni humanos ni monstruos, sino más bien las suma de ambos. No obstante, pueden advertirse maniobras desorientadoras exhibiendo un intersticio en el que todo puede suceder. 
BiBLIOGRAFÍA

Abrams, J.J., Jeffry Lieber y Damon Lindelof (2004-2010): Lost, ABC Studios, Estados Unidos.

Álvarez Berciano, Rosa (1999): «Series norteamericanas. La fórmula del éxito», en Lorenzo Vilches (coord.), Taller de escritura para televisión, Gedisa, Barcelona.

BARRENECHEA, Ana María (1996): «La literatura fantástica: función de los códigos socioculturales en la constitución de un tipo de discurso», en Saúl Sosnowski (ed.), Lectura crítica de la literatura americana. Inventarios, invenciones y revisiones, Fundación Biblioteca Ayacucho, Caracas.

BoIA, Lucian (1997): Entre el ángel y la bestia. El mito del hombre diferente desde la Antigüedad hasta nuestros días, Editorial Andrés Bello, Barcelona.

BORT Gual, Iván (2011): «Narrativa a la deriva: de Perdidos a la eternidad», L'Atalante, Revista de Estudios Cinematográficos, núm. 11 (enero/junio), pp. 52-59.

Buonnano, Milly (1999): El drama televisivo. Identidad y contenidos sociales, Estudios de Televisión núm. 3, Gedisa Editorial, Barcelona.

Buckland, Warren (2009): Puzzle Films. Complex Storytelling in Contemporary Cinema, Blackwell Publishing, Estados Unidos. <http:/ /dx.doi.org/10.1002/9781444305708>

CAlabrese, Omar (1994): La era neobarroca, Cátedra, Buenos Aires.

CALLeja, Seve (2005): Desdichados monstruos. La imagen deformante y grotesca del otro, Ediciones de la Torre, Madrid.

Carpenter, Stephen, David Greenwalt y Jim Kouf (2011-2014): Grimm, NBC, Estados Unidos.

Cascajosa Virino, Concepción (2005): Prime Time Las mejores series de TV americanas de CSI a Los Sopranos, Calamar Ediciones, Madrid.

CASCAJOSA VIRINO, Concepción (2006): «Miedos y sueños en Sunnydale: una aproximación a Joss Whedon como autor televisivo en Buffy, Cazavampiros», Garoza: Revista de la Sociedad Española de Estudios Literarios de Cultura Popular, núm. 6, pp. 61-82.

Colombres, Adolfo (1994-1995): «Del mito al cuento», Oralidad. Rescate de la tradición oral y la memoria de América latina y el Caribe, Anuario 6 y 7, Editorial Pueblo y Educación, La Habana.

Del Teso, Pablo (2011): Desarrollo de Proyectos Audiovisuales, Nokubo, Buenos Aires.

EliAde, Mircea (1968): Mito y realidad, Guadarrama, Madrid.

GALÁN FAJARDO, Elena (2007): «Fundamentos básicos en la construcción del personaje para medios audiovisuales», Revista del CES Felipe II, núm. 7, 2007, disponible en: <http:/ /hdl.handle.net/10016/5554> [Fecha de consulta: 08/01/2014].

García GuaL, Carlos (1987): La mitología: interpretaciones del pensamiento mítico, Biblioteca de Divulgación Temática/43, Montesinos.

GarCía RAmos, Arturo (1987): «Mímesis y verosimilitud en el cuento fantástico hispanoamericano", Anales de Literatura Hispanoamericana, núm. 16, pp. 81-94.

GLOCKNER, Julio (1994): «Viejos y nuevos monstruos», Elementos, núm. 22, vol. 3, pp. 35-42. 
GuÀrdiA CALVO, Isadora (2007): «Tantas caperucitas como lobos», Extravío. Revista electrónica de literatura comparada, núm. 2, disponible en <http:/ / www.uv.es/extravio/ pdf2/i_guardia.pdf $>$ [Fecha de consulta: 05/04/2014]

Herrero Cecilia, Juan (2000): Estética y pragmática del relato fantástico: las estrategias narrativas y la cooperación interpretativa del lector, Editorial Cuenca, Universidad de Castilla-La Mancha.

KIRK, G. S. (1985): El Mito. Su significado y funciones en la antigüedad y otras culturas, Paidós Ibérica, Barcelona.

Kitsis, Edward y Adam Horowitz (2011-2013): Once Upon A Time, ABC, Estados Unidos.

KROTZ, Esteban (2004):«Alteridad y pregunta antropológica», en M. Boivin, A. Rosato, y V. Arribas, Constructores de Otredad. Una introducción a la Antropología Social y Cultural, Antropofagia, Buenos Aires.

MitTell, Jason (2006): «Narrative Complexity in Contemporary American Television», The Velvet Light Trap, núm. 58, pp. 29-40.

<http:/ /dx.doi.org/10.1353/vlt.2006.0032>

Orenstein, Catherine (2003): Caperucita al desnudo, Ares y Mares, Barcelona.

Pérez Pereiro, Martín (2010): «Alegoría televisiva post 11-S. La imaginación terrorista en la ficción seriada norteamericana», en Esther Gaytán, Fátima Gil y Maria Ulled (eds.), Los mensajeros del miedo. Las imágenes como testigos y agentes del terrorismo, Ediciones RIALP, Madrid.

Reguillo, Rossana (2000): «Los laberintos del miedo. Un recorrido para fin de siglo», Revista de estudios sociales, núm. 5.

Río PARRA, Elena (2003): Una era de monstruos: representaciones de lo deforme en el Siglo de Oro español, Iberoamericana, Madrid.

ROAS, David (2006): «Hacia una teoría sobre el miedo y lo fantástico», Revista Semiosis (México), II, núm. 3 (enero/junio), pp. 95-116.

SANTIESTEBAn, Héctor (2000): «El monstruo y su ser», Relaciones, vol. XXI, núm. 81, pp. 95-126.

Todorov, Tzvetan (2005): Introducción a la literatura fantástica, Coyoacán, México.

TOLKIEN, John Ronald Reuel (1998): «Sobre los cuentos de hadas», en Los monstruos y los críticos y otros ensayos, Minotauro, Barcelona.

Tous Rovirosa, Anna (2008): Temas y tramas de la narrativa serializada de los Estados Unidos, Observatorio de la Producción Audiovisual (OPA), Barcelona.

Tous Rovirosa, Anna (2009): El surgimiento de un nuevo imaginario en la ficción televisiva de calidad, Quaderns del CAC, Barcelona.

Tous Rovirosa, Anna (2009): «Paleotelevisión, neotelevisión y metatelevisión en las series dramáticas estadounidenses», Comunicar, vol. XVII, núm. 33, pp. 175-183. <http:/ /dx.doi.org/10.3916/c33-2009-03-009>

Vilches, Lorenzo (1999): Taller de escritura para televisión, Gedisa, Barcelona.

Whedon, Joss (1997-2001): Buffy, la cazavampiros, The WB, Estados Unidos.

Whithouse, Toby (2008-2013): Being human (UK), BBC THREE, Reino Unido.

Whithouse, Toby (2011-2014): Being Human (US), SyFy- Muse Entertainmenr Enterprises, Estados Unidos. 